\title{
Impact of Anti-GPIIb/IIla Antibody-Producing B Cells as a Predictor of the Response to Lusutrombopag in Thrombocytopenic Patients with Liver Disease
}

\author{
Naohisa Wada ${ }^{a}$ Haruki Uojima $^{a}$ Takashi Satoh $^{c, d}$ Sosei Okina ${ }^{e}$ \\ Shuichiro Iwasaki $^{a}$ Xue Shao $^{a}$ Hayato Takiguchid ${ }^{d}$ Yoshitaka Arase $^{f}$ \\ Norio Itokawa ${ }^{g}$ Masanori Atsukawa ${ }^{h}$ Koji Miyazaki ${ }^{i}$ Hisashi Hidaka ${ }^{a}$ \\ Makoto Kako ${ }^{\text {b }}$ Tatehiro Kagawa $^{f}$ Katsuhiko Iwakirig Ryouichi Horie ${ }^{c, d}$

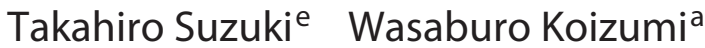

\begin{abstract}
aDepartment of Gastroenterology, Internal Medicine, Kitasato University School of Medicine, Sagamihara, Japan; bDepartment of Gastroenterology, Shonan Kamakura General Hospital, Kamakura, Japan; 'Division of Hematology, Department of Medical Laboratory Sciences, Kitasato University School of Allied Health Sciences, Sagamihara, Japan; 'Division of Molecular Hematology, Kitasato University Graduate School of Medical Sciences, Sagamihara, Japan; 'Department of Hematology, Internal Medicine, Kitasato University School of Medicine, Sagamihara, Japan; fDivision of Gastroenterology and Hepatology, Department of Internal Medicine, Tokai University School of Medicine, Sagamihara, Japan; 9 Department of Internal Medicine, Division of Gastroenterology, Nippon Medical School Chiba Hokusoh Hospital, Chiba, Japan; hepartment of Internal Medicine, Division of Gastroenterology and Hepatology, Nippon Medical School, Tokyo, Japan; 'Department of Transfusion and Cell Transplantation, Kitasato University School of Medicine, Sagamihara, Japan
\end{abstract}

\section{Keywords}

Anti-GPIIb/IIla antibody-producing B cells · Chronic liver disease · Lusutrombopag · Thrombocytopenia · Thrombopoietin receptor agonist

\begin{abstract}
Background: To make an accurate estimate of the response to thrombopoietin (TPO) receptor agonists for thrombocytopenia associated with chronic liver disease, we evaluated the influence of antiplatelet autoantibodies on the response to lusutrombopag in thrombocytopenic patients with liver disease. Methods: A prospective study was conducted at 2 hospitals. Thrombocytopenic patients with liver disease re-
\end{abstract}

karger@karger.com www.karger.com/ddi

Karger $\stackrel{\text { ' }}{5}$

BOPEN ACCESS
(C) 2020 The Author(s)

Published by S. Karger AG, Basel

This article is licensed under the Creative Commons AttributionNonCommercial-NoDerivatives 4.0 International License (CC BYNC-ND) (http://www.karger.com/Services/OpenAccessLicense). Usage and distribution for commercial purposes as well as any distribution of modified material requires written permission. ceived oral lusutrombopag $3.0 \mathrm{mg}$ once daily for up to 7 days. We analyzed changes in platelet counts from baseline to the maximum platelet count on days 9-14. The definition of clinical response was a platelet count of $\geq 5 \times 10^{4} / \mu \mathrm{L}$ with an increased platelet count of $\geq 2 \times 10^{4} / \mu \mathrm{L}$ from baseline. We assessed the correlation between the response to treatment drug and antiplatelet autoantibodies measured by anti-GPIIb/Illa antibody-producing B cells. Results: Thirty patients received the trial drug. There were 25 responders and 5 nonresponders. The median change in platelet counts was $3.9 \times$ $10^{4} / \mu \mathrm{L}(95 \% \mathrm{Cl} 2.8-4.6, p<0.0001)$. The correlation between change in platelet counts and the frequency of the anti-glycoprotein Ilb/llla antibody-producing B cells was moderate $(r=0.414,95 \% \mathrm{Cl} 0.064-0.674, p=0.023)$. In multivariate 
analysis of factors affecting the change in platelet counts, the anti-GPIIb/IIla antibody-producing B cells were identified as an independent factor (regression coefficient $[B]=$ 0.089; Cl 0.021-0.157, $p=0.013$ ). Conclusion: Anti-GPIIb/IIla antibody-producing $B$ cells may be a predictor for TPO receptor agonists in patients with chronic liver disease.

(C) 2020 The Author(s)

Published by S. Karger AG, Basel

\section{Introduction}

Thrombopoietin (TPO), which is produced by functional liver cells, is the major controller of circulating platelet production by TPO receptors on the megakaryocyte cell surface [1-3]. One of the reasons for the thrombocytopenia in end-stage liver disease is decreased TPO production $[4,5]$.

Lusutrombopag is a TPO receptor agonist (TPO-RA) for thrombocytopenic patients who have chronic hepatitis and liver cirrhosis [6-8]. For thrombocytopenic patients with inadequate TPO production, TPO-RAs are an ideal treatment drug aimed to increase megakaryocytes through interactions with the TPO receptors on the surface of bone marrow cells $[9,10]$.

We reported that spleen size is a good predictor for clinical response of lusutrombopag in terms of platelet count [11]. Historically, thrombocytopenia in chronic liver disease has been caused by sequestration and/or increased destruction in a spleen enlarged by congestive splenomegaly secondary to portal hypertension [12]. Therefore, if TPO-RAs had a good clinical response, severe splenomegaly could reduce the efficacy because of increased splenic destruction and sequestration, resulting in reduced platelet counts. However, one phase 3 study showed different results in different cohorts [6]. This is because there are variations from person to person in the multiple factors that contribute to the thrombocytopenia associated with chronic liver disease. Immune-mediated destruction involving antiplatelet antibodies is frequently present in chronic liver disease and is one of the causes of thrombocytopenia [13].

There is extensive evidence that platelets coated by antiplatelet autoantibodies are recognized by macrophages in the spleen, leading to accelerated platelet consumption [14]. To make an accurate estimate of the response to TPO-RAs for thrombocytopenia associated with chronic liver disease, the influence of antiplatelet autoantibodies on the response to TPO-RAs needs to be evaluated in more detail. Therefore, we aimed to assess the influence of the antiplatelet autoantibodies for the response to TPO-RAs in thrombocytopenic patients with liver disease.

\section{Materials and Methods}

\section{Eligibility Criteria}

A prospective study was conducted at 2 hospitals in Japan. Patients with thrombocytopenia due to chronic liver disease were included. Liver disease in these patients was caused by nonalcoholic fatty liver disease, alcoholic liver disease, viral infection with hepatitis $B$ and $C$ virus, and autoimmune disease. Patients with medical history of splenectomy, history of portal vein thrombosis, Child-Pugh class $\mathrm{C}$ liver disorder, other causes of thrombocytopenia, history of thromboembolism, or blood transfusions in the previous 2 weeks were excluded. To exclude hematologic disease, including primary immune thrombocytopenia (ITP), bone marrow puncture and/or biopsy was performed by a hematologist for the enrolled patients.

\section{Study Design}

The study design consisted of a screening period followed by a 28-day treatment period. Patients who met the eligibility criteria received oral lusutrombopag at $3.0 \mathrm{mg}$ once daily, starting on day 1 of the treatment period and continuing for up to 7 days. For those patients, we analyzed changes in platelet counts on day 5 to prevent an excessive increase in platelet count reporting and calculated platelet counts after the administration of lusutrombopag on days 9-12. Concomitant drug therapies that influence platelet counts were not changed if the patients were taking them prior to enrollment in the clinical trial.

We analyzed changes in platelet counts and treatment responses after administration of the trial drug from blood samples on day 1 and the maximum platelet count on days 9-14. The definition of clinical response was a platelet count of $\geq 5 \times 10^{4} / \mu \mathrm{L}$ with an increased platelet count of $\geq 2 \times 10^{4} / \mu \mathrm{L}$ from baseline after administration of the trial drug [8].

To assess the influence of antiplatelet autoantibodies in the response to TPO-RAs, we evaluated the correlation between the increased platelet counts after administration of the trial drug and antiplatelet autoantibodies. The presence of antiplatelet autoantibodies was proven by the existence of platelet-associated immunoglobulin G (PAIgG) and anti-glycoprotein IIb/IIIa antibody-producing B cells. The PAIgG was measured on intact and lysed platelets using an immunoradiometric assay [15]. The anti-GPIIb/IIIa antibody-producing $\mathrm{B}$ cells were detected using the enzyme-linked immunospot (ELISPOT) assay [16]. The details of the ELISPOT assay are given below.

A polyvinylidene difluoride-bottomed 96-well microplate, which was activated with ethanol for incubation, was coated with affinity-purified human GPIIb/IIIa dissolved in PBS containing $0.5 \mathrm{mM} \mathrm{CaCl}_{2}$ (PBS-Ca). Peripheral blood mononuclear cells (PBMCs) isolated from the enrolled patients were pipetted into the wells and cultured at $37^{\circ} \mathrm{C}$ with $5 \% \mathrm{CO}_{2}$ for $4 \mathrm{~h}$. During this incubation period, secreted anti-GPIIb/IIIa antibodies were bound to the immobilized GPIIb/IIIa in the immediate vicinity of the secreting cells. After washing away the cells with PBS-Ca containing $0.05 \%$ Tween 20 , anti-GPIIb/IIIa antibodies that were bound to 
Table 1. Baseline clinical characteristics

\begin{tabular}{|c|c|}
\hline \multicolumn{2}{|l|}{ Clinical characteristics } \\
\hline$N$ & 30 \\
\hline Age, years & $68.5(48-83)$ \\
\hline Gender: male, $n(\%)$ & $19(63.3)$ \\
\hline Height, m & $1.61(1.46-1.88)$ \\
\hline Weight, kg & $57.2(46-91)$ \\
\hline BMI, $\mathrm{kg} / \mathrm{m}^{2}$ & $22.6(18.5-31.1)$ \\
\hline Etiology: HCV/HBV/alcohol and NASH/others, $n$ & $11 / 3 / 12 / 4$ \\
\hline Liver cancer, $n(\%)$ & $15(50)$ \\
\hline Splenic volume, $\mathrm{mL}$ & $724(124-1,499)$ \\
\hline Child-Pugh & $6(5-9)$ \\
\hline MELD & $5(2-15)$ \\
\hline Platelets, $\times 10^{4} / \mu \mathrm{L}$ & $4.51(1.7-4.9)$ \\
\hline Immature platelet fraction, $\%$ & $5.95(1.5-10.5)$ \\
\hline Megakaryocytes $<15 / \mu \mathrm{L}, n(\%)$ & $21(70)$ \\
\hline $\mathrm{TPO}<0.4 \mathrm{fmol} / \mathrm{mL}, n(\%)$ & $22(73.3)$ \\
\hline Platelet-associated immunoglobulin, $\mathrm{ng} / \mathrm{mL} / 10^{7}$ cells & $82(20-630)$ \\
\hline Anti-glycoprotein IIb/IIIa antibody-producing B cells, /10 5 PBCs & $14.1(0.25-37.7)$ \\
\hline $\mathrm{WBCs}, / \mu \mathrm{L}$ & $3,150(1,400-4,800)$ \\
\hline Hemoglobin, g/dL & $12.5(7.5-15.6)$ \\
\hline Prothrombin time, $\%$ & $68.5(45-100)$ \\
\hline Serum albumin, g/dL & $3.6(2.2-4.5)$ \\
\hline BUN, mg/dL & $15.2(6.70-56.5)$ \\
\hline Serum $\mathrm{Cr}, \mathrm{mg} / \mathrm{dL}$ & $0.72(0.48-2.29)$ \\
\hline Aspartate aminotransferase, IU/L & $35.5(18-133)$ \\
\hline Alanine aminotransferase, IU/L & $27.5(9-121)$ \\
\hline Total bilirubin, $\mathrm{g} / \mathrm{dL}$ & $1.2(0.4-2.8)$ \\
\hline Ammonia, $\mu \mathrm{g} / \mathrm{dL}$ & $60(12-210)$ \\
\hline $\mathrm{AFP}, \mathrm{ng} / \mathrm{mL}$ & $5(2-596)$ \\
\hline PIVKA-II, mAU/mL & $20(11-476)$ \\
\hline Procedures: RFA/IVR/endoscopy/others, $n$ & $9 / 10 / 6 / 5$ \\
\hline
\end{tabular}

Data are expressed as median range or $n(\%)$. AFP, $\alpha$-fetoprotein; NASH, nonalcoholic steatohepatitis; MELD, model for end-stage liver disease; APRI, aspartate aminotransferase to platelet ratio index; FIB-4, Fibrosis-4 Index; PIVKA, protein induced by vitamin $\mathrm{K}$ absence; RFA, radiofrequency ablation; IVR, interventional radiology; TPO, thrombopoietin.

the membrane were incubated with a nitroblue tetrazolium/5-bromo-4-chloro-3-indolyl phosphate to facilitate visualization. Each assay was conducted in 4 independent wells, and the mean of 4 values was determined. The frequency of anti-GPIIb/IIIa antibody-producing $\mathrm{B}$ cells was expressed as the number $/ 10^{5}$ per PBMCs, and the cutoff value was defined as $2.0 / 10^{5}$ per PBMCs. The inter- and intra-laboratory reproducibility of the ELISPOT assay was evaluated by multiple laboratories $[16,17]$. Furthermore, we performed the simulation using peripheral blood collected from 3 ITP patients, 5 liver cirrhosis patients, and 3 healthy controls to evaluate the intra- and inter-laboratory reproducibility of an ELISPOT assay. As a result, the ELISPOT assay demonstrated a good intra- and inter-laboratory reproducibility. Data collected at baseline included demographic information, concomitant medications, physical characteristics, and laboratory tests in the pretreatment screening period.

Measurement of splenic volume was calculated based on computed tomography during a 6-month period [8]. The laboratory parameters was WBC count, platelet count, hemoglobin, aspartate aminotransferase, alanine aminotransferase, BUN, Cr, total protein level, albumin, total bilirubin, a-fetoprotein, percent prothrombin time, and TPO. Serum TPO levels from enrolled patients were measured using a quantitative ELISA. The lower limit of quantification was $0.4 \mathrm{fmol} / \mathrm{mL}$.

\section{Statistical Analyses}

We analyzed all the enrolled patients who had received lusutrombopag at least once. All statistical analyses were performed using IBM ${ }^{\circledR}$ SPSS $^{\circledR}$ software, version 24.0 (IBM Corporation, Armonk, NY, USA). $p$ values $<0.05$ were considered statistically significant. The paired data for enrolled patients were compared using the Wilcoxon signed rank test. Responders and nonresponders were compared using the Mann-Whitney $U$ test. Differences in frequency between the 2 groups were examined using the $\chi^{2}$ test. Correlations between the antiplatelet autoantibodies and change in platelet counts were determined using Pearson's product mo- 


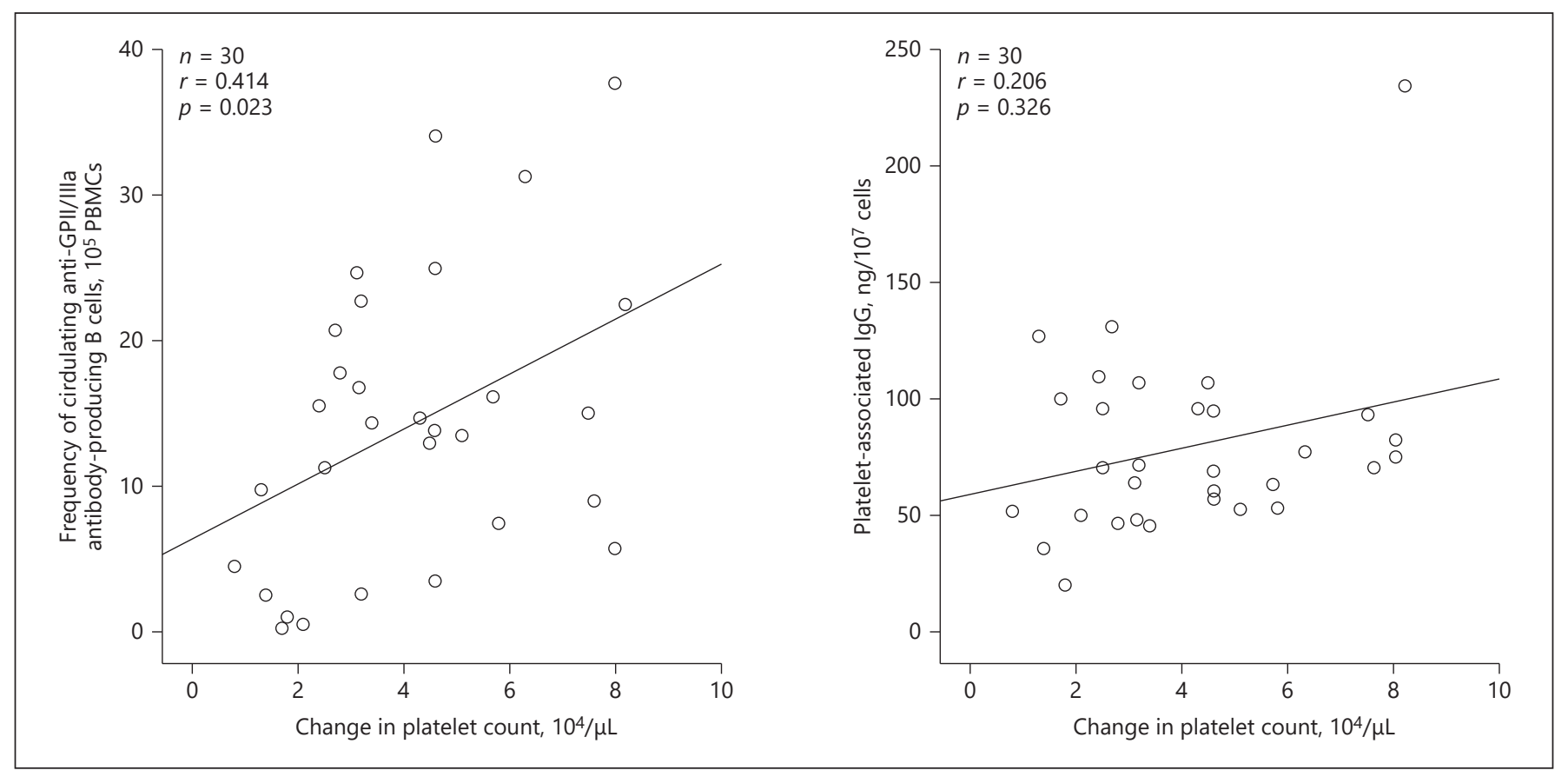

Fig. 1. Correlation between change in platelet count and antiplatelet autoantibodies, determined using Pearson's $r$ coefficient. PAIgG, platelet-associated immunoglobulin G.

ment correlation coefficient. Multivariate linear regression analyses were performed to assess the correlation between the changes in platelet counts and antiplatelet autoantibodies. Statistical data analyses were performed by Statista (Kyoto, Japan).

\section{Results}

\section{Patients' Characteristics}

Thirty-four patients were enrolled from January 2017 through November 2019. During the run-in period, 4 patients dropped out of the clinical study ( 2 patients had hematologic disease and 2 had Child-Pugh class $\mathrm{C}$ liver disorder). Table 1 shows the characteristics of the remaining 30 patients.

A total of 19 patients (63.3\%) were male. The median age of the patients was 68.5 years (range $48-83$ years), and the median body weight was $57.2 \mathrm{~kg}$ (range $46.0-91.0 \mathrm{~kg}$ ), and the median BMI was 22.6 (range 18.5-31.1). Liver disease was caused by viral and nonviral hepatitis $(n=14$ and 16, respectively). Fifteen patients (50.0\%) had liver cancer. TPO levels with the lower limits of quantification were observed in 22 patients (73.3\%). A bone marrow examination showed a decreased production of megakaryocytes. The frequency of anti-GPIIb/IIIa antibody-pro- ducing B cells was 14.1/10 PBMCs (range, 0.25-37.7). The median PAIgG level was $82 \mathrm{ng} / 10^{7}$ cells (range, 20 630).

\section{Clinical Response after Administration of the Trial Drug}

All enrolled patients received oral lusutrombopag at $3.0 \mathrm{mg}$ daily for 7 days. The platelet count was significantly increased after administration of a trial drug. The median change in platelet counts was $3.9 \times 10^{4} / \mu \mathrm{L}(95 \%$ CI 2.8-4.6, $p<0.0001)$.

There were $25(83.3 \%)$ responders and 5 (16.7\%) nonresponders. Although 3 nonresponders received platelet transfusions before the invasive treatment, there were no instances of spontaneous bleeding after the procedures.

\section{Correlation between Antiplatelet Autoantibodies and} the Change in Platelet Counts

Regarding the correlation between antiplatelet autoantibodies and the increased platelet counts after administration of the trial drug using Pearson's $r$ coefficient, the correlation coefficients of anti-GPIIb/IIIa antibody-producing B cells and PAIgG were 0.414 and 0.206 , respectively (Fig. 1). Anti-GPIIb-IIIa antibody-producing B cells were associated with a change in platelet count $(95 \%$ 
Table 2. Univariate analyses and multivariate analysis of factors affecting the change in platelet counts

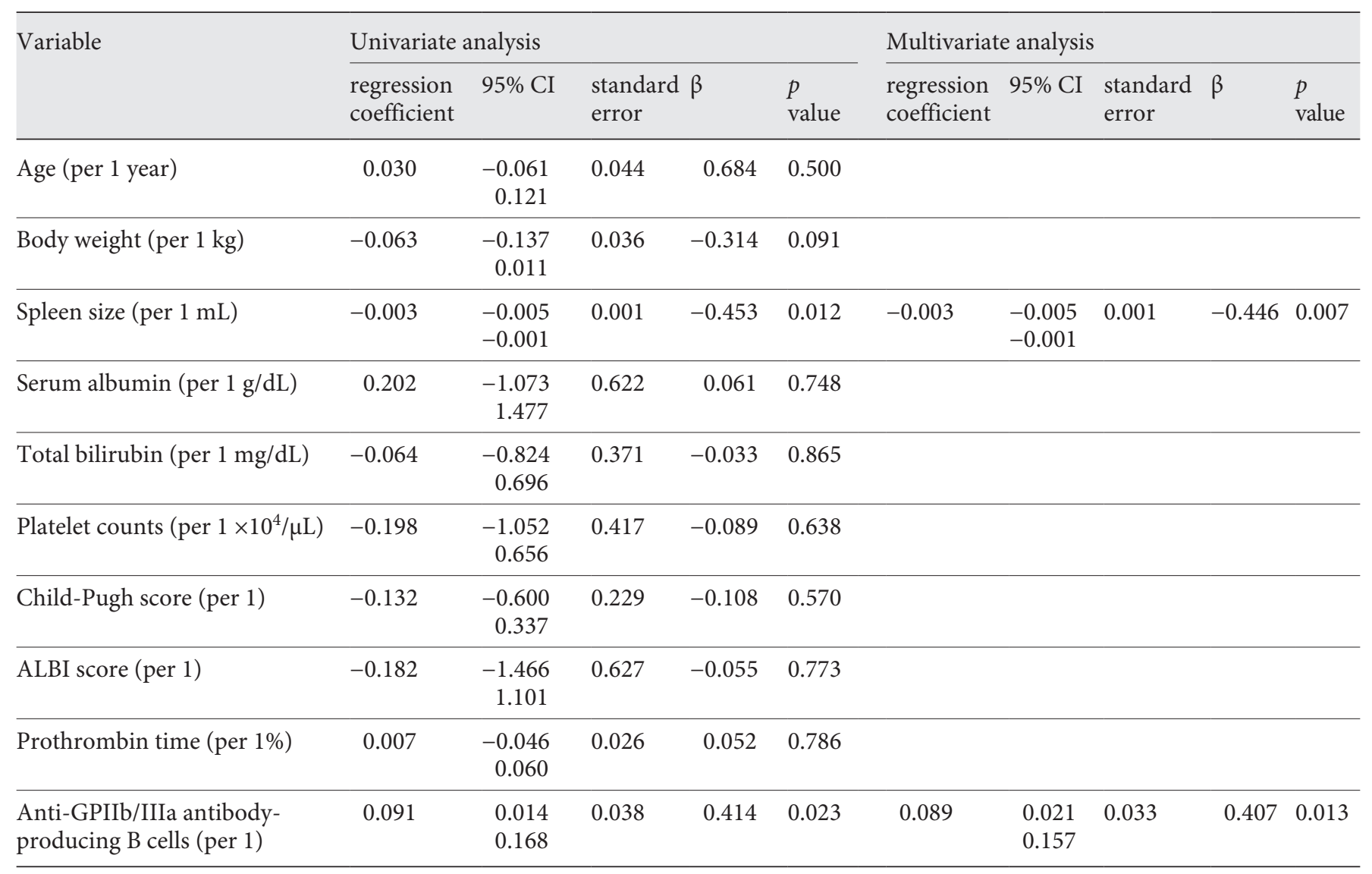

CI $0.064-0.674, p=0.023)$. However, PAIgG was not associated with a change in platelet count $(95 \% \mathrm{CI}-0.207$ to $0.555, p=0.326$ ).

We also evaluated the relation between change in platelet counts and the antiplatelet autoantibodies in multivariate linear regression analysis (Table 2). Regarding the candidates for multivariate analysis, we selected variable factors which have a significant univariate test result based on $p$ value cutoff point of 0.25 . Therefore, body weight, spleen size, and anti-GPIIb/IIIa antibodyproducing B cells were identified according to the univariate analyses. Multivariate analyses confirmed that spleen size and anti-GPIIb/IIIa antibody-producing B cells were independent of the responder (regression coefficient $[B]=-0.003,95 \% \mathrm{CI}-0.005$ to $-0.001, p=0.007$ and regression coefficient $[B]=0.089,95 \%$ CI $0.021-$ $0.157, p=0.013$, respectively).

\section{Analyses of the Antiplatelet Autoantibodies in \\ Responders}

The frequency of anti-GPIIb-IIIa antibody-producing B cells in responders after administration of lusutrombopag was significantly higher than that in nonresponders (15.0 vs. $2.5 / 10^{5}$ PBMCs, $p=0.004$ ) (Fig. 2). However, there was no significant difference between responders and nonresponders in the frequency of PAIgG (51.7 vs. $87.5 \mathrm{ng} / 10^{7}$ cells, $p=0.315$ ).

\section{Analyses of the Antiplatelet Autoantibodies in Adverse Events}

The incidences of adverse events are summarized in Table 3. There were no treatment-related deaths or grade $\geq 3$ treatment-related adverse events. There were 6 patients with any grade of AEs who suffered fever, aspartate aminotransferase increase, gastrointestinal disorders, and hypertension during treatment. No significant differences between patients with and without adverse events were found with respect to the frequency of anti-GPIIb- 


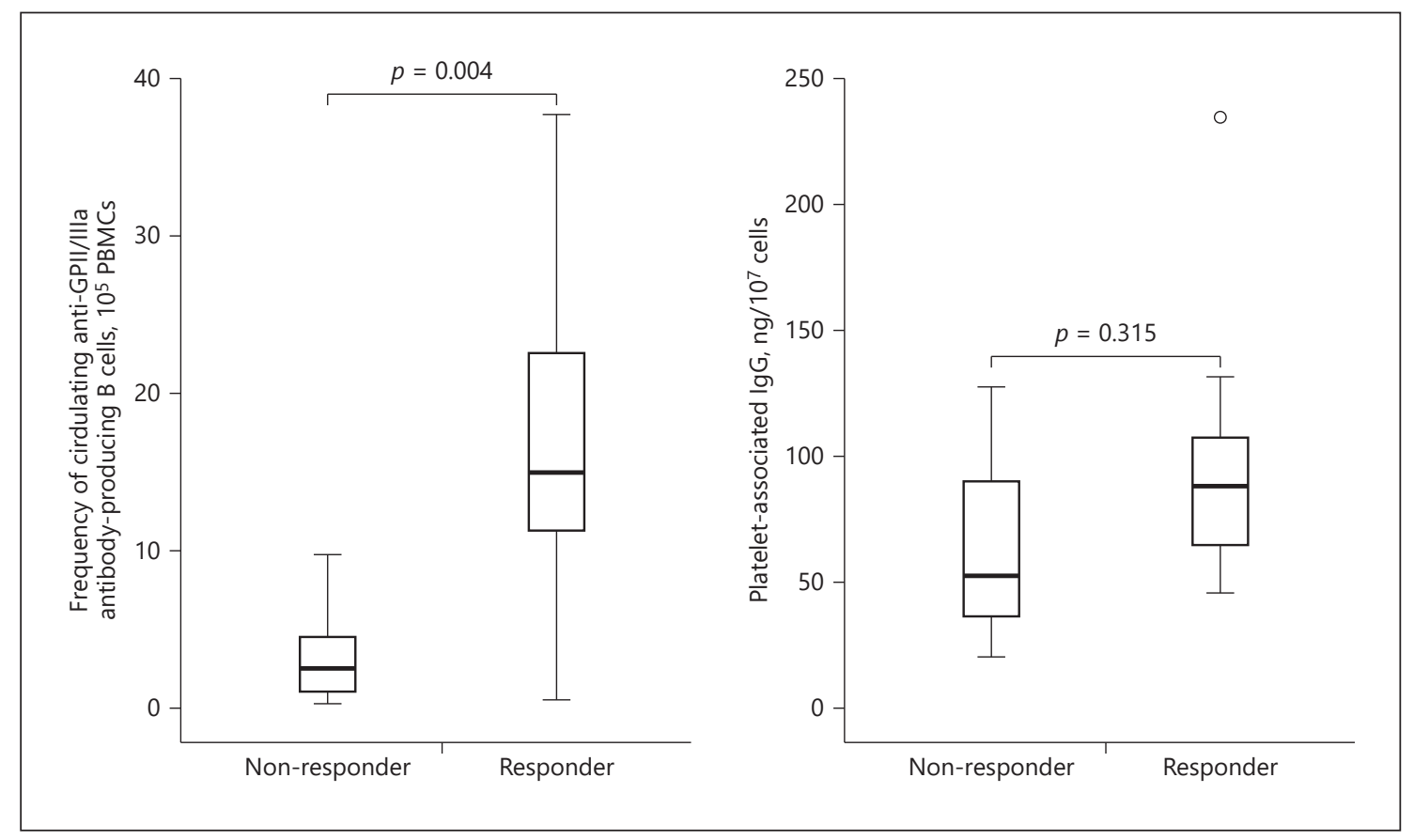

Fig. 2. Comparison of antiplatelet autoantibodies and response after administration of the trial drug. Data are expressed as mean \pm SD. Separate analyses of complications were compared using the Mann-Whitney U test. PAIgG, platelet-associated immunoglobulin G.

Table 3. Adverse events

\begin{tabular}{lll}
\hline Adverse events & Grade & $N(\%)$ \\
\hline Fever & Any & $2(6.6)$ \\
& $\geq 3$ & 0 \\
\hline Aspartate aminotransferase increased & Any & $2(6.6)$ \\
& $\geq 3$ & 0 \\
\hline Gastrointestinal disorders & Any & $1(3.3)$ \\
& $\geq 3$ & 0 \\
\hline Hypertension & Any & $1(3.3)$ \\
& $\geq 3$ & 0 \\
\hline Portal thrombosis & Any & 0 \\
& $\geq 3$ & 0 \\
\hline
\end{tabular}

IIIa antibody-producing B cells (13.9 vs. 14.3/10 $\mathrm{PBMCs,}$ $95 \% \mathrm{CI}-1.01$ to $4.52, p=0.717$ ).

\section{The Scatter Plot of Antiplatelet Autoantibodies and}

Spleen Volume in Nonresponders

There was also no correlation between the frequency of anti-GPIIb/IIIa antibody-producing B cells and spleen volume. However, high frequency of anti-GPIIb/IIIa an- tibody-producing B cells and smaller spleen size were associated with a lack of clinical response (Fig. 3). Three nonresponders received platelet transfusions before invasive treatment. All patients who received platelet transfusions had low frequencies of anti-GPIIb/IIIa antibodyproducing B cells.

\section{Discussion}

To our knowledge, this is the first report that suggests that the level of antiplatelet autoantibodies may play a role as a predictor for response to TPO-RAs. This clinical study showed that the frequency of anti-GPIIb/IIIa antibody-producing B cell levels was correlated with the response for lusutrombopag in severe thrombocytopenic patients due to chronic hepatitis and liver cirrhosis. In patients who had chronic hepatitis, autoantibodies directed against platelet surface antigens lead to accelerated platelet consumption by the spleen and triggered their rapid destruction, as observed in chronic ITP $[18,19]$. In terms of thrombocytopenia, the key difference between chronic liver disease and chronic ITP is the plasma TPO levels [20]. Plasma TPO levels in ITP patients are normal 
Fig. 3. Scatter plot of antiplatelet autoantibodies and spleen size in responders and nonresponders. White mark, responders; blue mark, nonresponders; red circle, patients who received platelet transfusions.

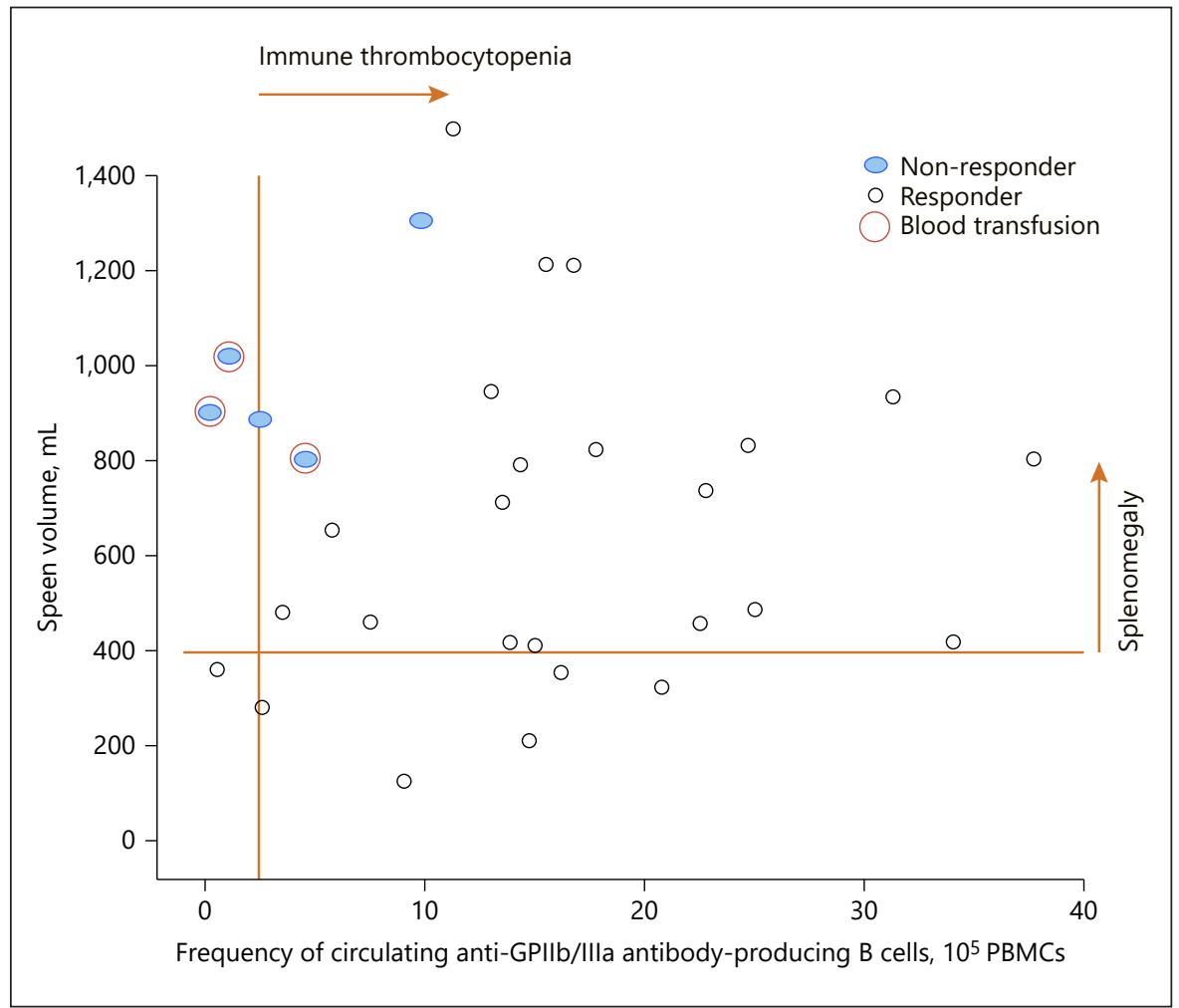

or minimally increased as a result of increased clearance of the hormone and binding to an expanded megakaryocyte mass [21]. On the other hand, chronic liver disease has very low TPO levels as a result of reduced TPO production by a severely damaged liver cell mass. Previously, researchers reported that TPO levels correlated with response to TPO-RAs in ITP patients, with higher TPO levels predicting a poor clinical response [22]. Therefore, low TPO levels in patients with chronic liver disease had a significant effect after administration of TPO-RAs.

As a predictor for response to TPO-RAs for thrombocytopenia associated with chronic liver disease, factors related to thrombocytopenia that lead to destruction of platelets within the spleen may be more clinically useful than those that lead to platelet production. This study cohort showed multiple factors related to thrombocytopenia, including decreased activity of the hematopoietic growth factor, bone marrow suppression, immune-mediated thrombocytopenia, and the pooling of platelets in the enlarged spleen caused by liver cirrhosis and portal hypertension. Most of the enrolled patients had low plasma TPO levels and severe thrombocytopenia in the bone marrow. On the other hand, a high frequency of anti-GPIIb/ IIIa antibody-producing B cells and smaller spleen size were associated with good clinical response. Platelets are destroyed by macrophages or platelet antigens degraded to peptides by dendritic cells, depending on the spleen size and the frequency of autoantibodies. If thrombocytopenic patients have small spleens with high frequency of autoantibodies, significant effects may be expected.

In the present study, we evaluated PAIgG and antiGPIIb/IIIa antibody-producing B cells as antiplatelet autoantibodies. The level of PAIgG was not associated with clinical response because PAIgG is increased in many patients with non-ITP. Anti-GPIIb/IIIa antibody-producing $B$ cells were reported to be highly sensitive and specific, compared with PAIgG, for evaluating the presence or absence of autoantibodies. GPIIb and IIIa, which are major platelet membrane proteins, are the most common targets of autoantibodies in patients with ITP [23, 24]. Although an inter-laboratory standardization of antiGPIIb/IIIa antibodies has been difficult to achieve, Kuwana et al. [16] established an ELISPOT assay for the detection of circulating B cells secreting IgG anti-GPIIb/IIIa antibodies. They also reported that the circulating $\mathrm{B}$ cells producing anti-GPIIb/IIIa antibodies for anti-platelet autoimmunity have a similar profile in patients with liver cirrhosis and ITP [25]. 
Recently, therapies for primary ITP have been directed to ameliorate the condition of impaired platelet production due to antiplatelet autoantibodies [26]. TPO-receptor agonists are a useful treatment for chronic ITP aimed at increasing megakaryocytes through interactions with the TPO receptors. If the levels of antiplatelet antibodies are similar in patients with ITP and patients with chronic liver disease, TPO-RA therapy is useful for thrombocytopenia due to immune-mediated thrombocytopenia in chronic liver disease. When administering TPO-RAs to patients with thrombocytopenia, clinicians should pay careful attention to the factors related to thrombocytopenia and take into account the destruction of platelets from antiplatelet antibodies.

This study had some limitations. First, the sample size is relatively small to draw definitive conclusions. Second, 4 patients were excluded according to the exclusion criteria. This may have been a sample selection bias. Third, in the present study, no patients received oral lusutrombopag daily for 5 or 6 days to prevent an excessive increase in platelet count. Therefore, we did not assess the impact of the discontinuation of the drug orally.

\section{Conclusion}

This clinical study showed the influence of antiplatelet autoantibodies on the response to TPO-RAs in patients with chronic hepatitis and liver cirrhosis. The frequency of anti-GPIIb/IIIa antibody-producing B cells may play a role as a predictor for the response to lusutrombopag.

\section{Acknowledgements}

We thank Statista Corporation, for assistance with the statistical analyses, and Robert E. Brandt, Founder, CEO, and CME of MedEd Japan, for editing and formatting the manuscript.

\section{Statement of Ethics}

This study was approved by the Institutional Review Board Ethics Committee at both institutes, and all patients provided written informed consent. This study is registered in the UMIN Clinical Trials Registry as UMIN 000025776.

\section{Conflict of Interest Statement}

The authors have no conflicts of interest to declare.

\section{Funding Sources}

The authors did not receive any funding.

\section{Author Contributions}

Wada N., Uojima H., Satoh T., Okina S., Iwasaki S., Shao X., Takiguchi H., Arase Y., Itokawa N., Atsukawa M., Miyazaki K., Hidaka H., Kako M., Kagawa T., Iwakiri K., Horie R., Suzuki T., and Koizumi W. contributed equally to this work; Uojima H., Wada N., Satoh T., Okina S., and Takiguchi H. collected and analyzed the data; Uojima H. drafted the manuscript; Hidaka H. designed and supervised the study; Iwasaki S., Shao X., Arase Y., Itokawa N., Atsukawa M., Miyazaki K., and Hidaka H. offered technical or material support. Kako M., Kagawa T., Iwakiri K., Horie R., Suzuki T., and Koizumi W. were general supervisors of the study group. All authors discussed the results and commented on and approved the manuscript for publication.

\section{References}

1 Hitchcock IS, Kaushansky K. Thrombopoietin from beginning to end. Br J Haematol. 2014 Apr;165(2):259-68.

2 Vainchenker W, Raslova H. Megakaryocyte polyploidization: role in platelet production. Platelets. 2019 Sep:1-10.

3 Miller JB, Figueroa EJ, Haug RM, Shah NL. Thrombocytopenia in chronic liver disease and the role of thrombopoietin agonists. Gastroenterol Hepatol. 2019 Jun;15(6):326-32.

4 Afdhal N, McHutchison J, Brown R, Jacobson I, Manns M, Poordad F, et al. Thrombocytopenia associated with chronic liver disease. J Hepatol. 2008 Jun;48(6):1000-7.
5 Gangireddy VGR, Kanneganti PC, Sridhar S, Talla S, Coleman T. Management of thrombocytopenia in advanced liver disease. Can J Gastroenterol Hepatol. 2014 Nov;28(10):558-64.

6 Hidaka H, Kurosaki M, Tanaka H, Kudo M, Abiru S, Igura T, et al. Lusutrombopag reduces need for platelet transfusion in patients with thrombocytopenia undergoing invasive procedures. Clin Gastroenterol Hepatol. 2019 May;17(6):1192-200.

7 Sasaki R, Shiino C, Imawari M, Bentley R, Cai B, Yoshida M, et al. Safety and effectiveness of lusutrombopag in Japanese chronic liver disease patients with thrombocytopenia undergoing invasive procedures: interim results of a postmarketing surveillance. Hepatol Res. 2019 Oct;49(10):1169-81.
8 Ishikawa T, Okoshi M, Tomiyoshi K, Kojima $\mathrm{Y}$, Horigome R, Imai M, et al. Efficacy and safety of repeated use of lusutrombopag prior to radiofrequency ablation in patients with recurrent hepatocellular carcinoma and thrombocytopenia. Hepatol Res. 2019 May;49(5): 590-3.

9 Nilles KM, Caldwell SH, Flamm SL. Thrombocytopenia and procedural prophylaxis in the era of thrombopoietin receptor agonists. Hepatol Commun. 2019 Sep;3(11):1423-34.

10 Abdela J. Current advance in thrombopoietin receptor agonists in the management of thrombocytopenia associated with chronic liver disease: focus on avatrombopag. Clin Med Insights Blood Disord. 2019 Oct; 12: 1179545X19875105. 
11 Uojima $\mathrm{H}$, Arase Y, Itokawa N, Atsukawa M, Satoh T, Miyazaki K, et al. Relationship between response to lusutrombopag and splenic volume. World J Gastroenterol. 2018 Dec; 24(46):5271-9.

12 Mitchell O, Feldman DM, Diakow M, Sigal $\mathrm{SH}$. The pathophysiology of thrombocytopenia in chronic liver disease. Hepat Med. 2016 Apr;8:39-50.

13 Cooper N, Ghanima W. Immune thrombocytopenia. N Engl J Med. 2019 Sep;381(10):94555.

14 Pereira J, Accatino L, Alfaro J, Brahm J, Hidalgo P, Mezzano D. Platelet autoantibodies in patients with chronic liver disease. Am J Hematol. 1995 Nov;50(3):173-8.

15 Gilli SC, de Souza Medina S, de Castro V, Fernandes LG, Saad ST. Platelet associated IgG may be related with thrombocytopenia in patients with myelodysplastic syndromes. Leuk Res. 2012 May;36(5):554-9.

16 Kuwana M, Kurata Y, Fujimura K, Fujisawa $\mathrm{K}$, Wada $\mathrm{H}$, Nagasawa T, et al. Preliminary laboratory based diagnostic criteria for immune thrombocytopenic purpura: evaluation by multi-center prospective study. J Thromb Haemost. 2006 Sep;4(9):1936-43.
17 Kuwana M, Okazaki Y, Satoh T, Asahi A, Kajihara M, Ikeda Y. Initial laboratory findings useful for predicting the diagnosis of idiopathic thrombocytopenic purpura. Am J Med. 2005 Sep;118(9):1026-33.

18 Ghanima W, Cooper N, Rodeghiero F, Godeau B, Bussel JB. Thrombopoietin receptor agonists: ten years later. Haematologica. 2019 Jun;104(6):1112-23.

19 González-Porras JRJR, Godeau BB, Carpenedo MM. Switching thrombopoietin receptor agonist treatments in patients with primary immune thrombocytopenia. Ther Adv Hematol. 2019 May;10:204062071983790.

20 Cooper KL, Fitzgerald P, Dillingham K, Helme K, Akehurst R. Romiplostim and eltrombopag for immune thrombocytopenia: methods for indirect comparison. Int J Technol Assess Health Care. 2012 Jul;28(3):24958.

21 Grotzinger KM, Younossi ZM, Giannini EG, Chen PJ, Rendas-Baum R, Theodore D. Health-related quality of life in thrombocytopenic patients with chronic hepatitis $C$ with or without cirrhosis in the ENABLE-1 and ENABLE-2 studies. Health Qual Life Outcomes. 2016 Mar; 14:49.
22 Al-Samkari H, Kuter DJ. Thrombopoietin level predicts response to treatment with eltrombopag and romiplostim in immune thrombocytopenia. Am J Hematol. 2018 Dec; 93(12):1501-8

23 Wong RSM, Saleh MN, Khelif A, Salama A, Portella MSO, Burgess P, et al. Safety and efficacy of long-term treatment of chronic/persistent ITP with eltrombopag: final results of the EXTEND study. Blood. 2017 Dec;130(23): 2527-36.

24 Elgebaly AS, Ashal GE, Elfil M, Menshawy A. Tolerability and efficacy of eltrombopag in chronic immune thrombocytopenia: metaanalysis of randomized controlled trials. Clin Appl Thromb Hemost. 2017 Nov;23(8):92837.

25 Kajihara M, Kato S, Okazaki Y, Kawakami Y, Ishii H, Ikeda Y, et al. A role of autoantibodymediated platelet destruction in thrombocytopenia in patients with cirrhosis. Hepatology. 2003 Jun;37(6):1267-76.

26 Wang L, Gao Z, Chen XP, Zhang HY, Yang N, Wang FY, et al. Efficacy and safety of thrombopoietin receptor agonists in patients with primary immune thrombocytopenia: a systematic review and meta-analysis. Sci Rep. 2016 Dec;6:39003. 